\title{
DISCRIMINAÇÃO RACIAL A IDENTIDADE E O PERTENCIMENTO: CRIANÇAS DE 9 E 10 ANOS
}

\author{
Anair Bongiovani ${ }^{1}$ \\ Roselaine Pereira dos Santos Costa Rodrigues ${ }^{2}$ \\ Rosecléia Pereira dos Santos ${ }^{3}$
}

Resumo: O trabalho aborda as relações raciais no ambiente escolar, com alunos do Ensino Fundamental I, tem por objetivo verificar a percepção dos alunos negros e brancos em relação ao preconceito, racismo e discriminação racial no espaço escolar a partir de sua vivência. Como acontece relação entre crianças brancas e negras no interior da escola, uma vez que a sociedade permeada pela exclusão, preconceito e discriminação racial. Os sujeitos da pesquisa foram alunos do Ensino Fundamental I, da Escola Municipal Menino Deus, de Lucas do Rio Verde- Mato Grosso, (MT) no ano de 2014. Observou-se que existem fatores no interior da escola que levam as crianças, a serem prejudicados em seu processo de escolarização, em alguns momentos são alvos de discriminação, por parte de colegas e professores. Para efeito deste trabalho, utilizou-se a abordagem qualitativa, que, preocupa-se com a pessoa e seus valores. Como instrumento de coleta de dados foi utilizado a entrevista semiestruturada com pauta guia, questionário auto administrado, utilizou-se também a observação participante, este tipo de pesquisa leva o pesquisador a participar da vida diária das pessoas com intuito de captar uma variedade de situações ou fenômenos vivenciados.

Palavras chaves: Pertencimento. Identidade. Discriminação.

\footnotetext{
${ }^{1}$ Mestranda em Educação pela UDE Montevidéu, Especialista em Gestão do Trabalho Pedagógico, Orientação e Supervisão Escolar, (FACINTER) Informática na Educação (UFMT) Pedagogia Empresarial (AVM) Relações Raciais na Sociedade Brasileira (UFMT), Pedagoga, (UFMT), Brasil. E-mail: anair.bongiovani@hotmail.com.

2 UNEMAT, Brasil. E-mail: rose.music@outlook.com.

${ }^{3}$ Graduanda de Letras - UNEMAT, Brasil. E-mail: rosesantos2428@gmail.com.
} 